\title{
Expresión del gen asociado con la resistencia múltiple a medicamentos (pfmdr1) en cepas colombianas de Plasmodium falciparum
}

\author{
Eliana P. Calvo', María O. Rojas ${ }^{1,2}$, Jacqueline Chaparro², Moisés Wasserman ${ }^{1,2}$
}

\begin{abstract}
Resumen
El tratamiento y control de la malaria ha sido obstaculizado por la capacidad del parásito para desarrollar resistencia a agentes antimaláricos. La cloroquina, que ha sido el principal agente antimalárico debido a su eficiencia, baja toxicidad y costo, ahora frecuentemente fracasa en el control de la enfermedad. El mecanismo por el cual los parásitos desarrollan resistencia a cloroquina no se ha establecido hasta el momento, aunque inicialmente la amplificación, sobre-expresión y mutaciones puntuales en un gen denominado pfmdr1 (Plasmodium falciparum multidrug resistant gene) fueron asociadas con el fenotipo cloroquinorresistente (CQR); estudios posteriores suscitaron controversia acerca de esta asociación. En el trabajo se estudió la expresión del gen pfmdr1 en las cepas colombianas de $P$. falciparum y en dos cepas de referencia, una sensible (Haití 135) y una resistente (Palo Alto), mediante un ensayo de slot-blot. Los resultados obtenidos permiten sugerir que la expresión del gen pfmdr1 no está directamente relacionada con el fenotipo resistente.
\end{abstract}

Palabras clave: Plasmodium, resistencia, fármacos, gen MDR, malaria.

Expresion of the multiple drug resistance associated gene (pfMDR 1) in Colombian strains of Plasmodium falciparum

\begin{abstract}
The treatment and control of malaria have confronted obstacles due to the parasite's capacity to develop resistance to antimalarial agents. Chloroquine, which has been the main agent against malaria due to its efficiency, low toxicity and cost, is now failing in the control of the disease. The mechanism through which the parasite develops resistance to chloroquine has not been defined yet, although the amplification, over-expression and point mutations found in a gene called pfmdr1 (Plasmodium falciparum multidrug resistance gene) were related to the chloroquine resistance phenotype (CQR). Nevertheless, later studies opened controversial discussion over such association. The present research work studied pfmdr1 gene's expression in Colombian strains of $P$. falciparum and in two reference strains: a sensitive one (Haiti 135) and a resistant one (Palo Alto), using a slot-blot test. The results obtained allow us to suggest that the pfmdr1 gene's expression is not directly related to the resistant phenotype.
\end{abstract}

Key words: Plasmodium, malaria, resistance, drugs, MDR-gene.

\footnotetext{
${ }^{1}$ Universidad Nacional de Colombia, Facultad de Ciencias, Departamento de Química, Santa Fe de Bogotá, D.C., Colombia

${ }^{2}$ Grupo de Bioquímica, Instituto Nacional de Salud, Santa Fe de Bogotá, D.C., Colombia

Recibido, mayo 5 de 1999; aceptado, agosto 26 de 1999
} 


\section{Introducción}

Los parásitos protozoarios son los agentes causantes de algunas de las enfermedades más devastadoras y prevalentes que afectan la población mundial; uno de tales patógenos, Plasmodium falciparum, es el agente causante de la forma más severa de malaria humana, enfermedad que, en muchas áreas del mundo tropical, sigue siendo uno de los principales problemas de salud. Cada año se presentan, por lo menos, 300 millones de nuevas infecciones, causando cerca de 2 millones de muertes en la población infantil principalmente (2). El tratamiento y control de esta enfermedad ha sido obstaculizado por la capacidad del parásito para desarrollar resistencia a los medicamentos en muchas áreas endémicas, aumentando la severidad del problema.

Es así como la cloroquina, principal agente antimalárico de uso común debido a su eficiencia, baja toxicidad y costo, ahora frecuentemente fracasa en el control de la enfermedad (1). Aunque otros antimálaricos sintéticos se encuentran disponibles, algunos presentan efectos colaterales, alto costo y, además, el parásito también llega a desarrollar resistencia. El mecanismo por el cual los parásitos adquieren resistencia a cloroquina no se ha establecido hasta el momento; de ahí que sean necesarios los estudios que lleven a un mejor entendimiento de las bases moleculares.

Los agentes quimioterapéuticos ampliamente utilizados para el control de esta enfermedad están reducidos a dos grupos: el primero, constituido por inhibidores de la vía de los folatos como la pirimetamina y el cicloguanil, y el segundo, por medicamentos derivados de la quinolina como la cloroquina, la mefloquina, la amodiaquina y la quinina.

Peterson, en 1988, pudo establecer que la resistencia in vitro a los inhibidores de la vía de los folatos es conferida por mutaciones puntuales en el gen de la dihidrofolatoreductasa (DFHR), mutaciones que llevan a modificaciones en la enzima blanco (3). Por el contrario, el mecanismo por el cual el parásito adquiere resistencia a medicamentos derivados de la quinolina no se ha establecido hasta el momento; el único rasgo persistente que distingue parásitos resistentes, es la disminución en la acumulación del medicamento en el interior del parásito.

Una de las hipótesis que se han formulado para explicar este fenómeno, se basa en experimentos realizados in vitroen los que se observa un rápido eflujo del medicamento desde el interior de la célula, eflujo que puede ser revertido por verapamil (4). Hallazgos análogos a éstos se habían reportado ya en células tumorales de mamífero resistentes a medicamentos, en las cuales el mecanismo de resistencia está definido por un aumento en el eflujo del medicamento mediado por una P-glicoproteína, localizada en la membrana plasmática de la célula y la cual funciona como una bomba de eflujo dependiente de ATP. La glicoproteína está codificada por un gen denominado MDR (gen de resistencia múltiple a drogas), el cual hace parte de una familia de genes MDR; los miembros de esta familia de genes se caracterizan por su amplificación y/o sobre-expresión en células tumorales de mamíferos resistentes a medicamentos (5). En 1989, se identificaron dos genes homólogos a MDR en P. falciparum, los cuales fueron denominados pfmdr1 y pfmdr2 (6). En estudios realizados posteriormente, se encontró el gen pfmdr1 amplificado y sobreexpresado en cepas resistentes a cloroquina, mefloquina y quinina; además se pudo establecer que la proteína producto del gen presenta las características típicas de las P-glicoproteínas, lo cual llevó a suponer que realmente en $P$. falciparum podía operar un mecanismo similar al que ocurre en mamíferos mediado por pfmdr1 (7).

En 1990, se presentaron serias evidencias que dejaban en entredicho la relación entre el gen pfmdr1 y la resistencia a medicamentos; se encontró que el fenotipo resistente no segregaba con el gen pfmdr1 en un cruce genético (8) y que se presentaba un aumento en la resistencia a cloroquina acompañada de una disminución en la expresión del gen y en el número de copias del mismo (9). En 1994, al expresar el tipo silvestre del gen pfmdr1 en células $\mathrm{CHO}$ (células de ovario de hámster chino), se observó un 
aumento en la sensibilidad a cloroquina, ocasionada por un aumento en la acumulación del medicamento, a partir de lo cual se postuló que la P-glicoproteína producto del gen podría estar mediando la acumulación de cloroquina y no su eflujo (10). Aunque en otros organismos se ha observado que la proteína producto del gen pfmdr1 puede actuar regulando el $\mathrm{pH}$ de organelos ácidos (11) y también como transportador de moléculas (12), su función en el parásito aun no se ha establecido.

Por otro lado, estudios recientes han identificado otros mecanismos que podrían dar origen al fenotipo resistente. Uno de ellos involucra un intercambiador $\mathrm{Na}^{+} / \mathrm{H}^{+}$como responsable del transporte del medicamento (13); la disminuida afinidad por éste en parásitos CQR, sugiere que la disminución en la acumulación de la cloroquina en el parásito es un evento mínimo necesario para que surja el fenotipo CQR (14). Adicionalmente, se han asociado complejos polimorfismos en una proteína denominada CG2, codificada por un segmento ubicado dentro del posible determinante de la CQR. Esta proteína se localiza en la periferia del parásito y en asociación con la hemozoína de la vacuola digestiva, donde se cree que ésta actúa (15).

Puesto que el gen pfmdr1 fue inicialmente asociado con la resistencia a cloroquina, a mefloquina y a otros medicamentos utilizados, y que los estudios realizados son controvertidos, es claro que se necesitan más estudios a nivel molecular que lleven a corroborar o refutar la relación entre el gen y el mecanismo que confiere resistencia a estos medicamentos. En este trabajo se estudió la expresión del gen pfmdr1 a lo largo del ciclo de vida asexual del parásito y su relación con la respuesta in vitro a medicamentos exhibida por diferentes cepas de $P$. falciparum. Se estudiaron las cepas colombianas FCB-1 y FCB-2 y se tomaron como referencia una cepa sensible (Haití 135) y otra resistente (Palo Alto).

\section{Materiales y métodos}

\section{Preparación de la sonda}

Para obtener una sonda específica, necesaria para reconocer el mensajero del gen pfmdr1 en cepas colombianas de P. falciparum, se amplificó un fragmento del gen utilizando la reacción en cadena de la ADN polimerasa (PCR) y un par de iniciadores específicos, diseñados con base en la secuencia del gen informada por Foote en 1989 (1); los oligos flanquean la región codificadora del gen comprendida entre el nucleótido 2 y 965 , dando lugar a un producto PCR de $963 \mathrm{pb}$. La reacción se llevó a cabo bajo las siguientes condiciones: buffer de la Taq polimerasa $(50 \mathrm{mM}$ de $\mathrm{KCl}, 10 \mathrm{mM}$ de Tris- $\mathrm{HCl} \mathrm{pH} 9,0$ a $25^{\circ} \mathrm{C}, 0,1 \%$ Tritón X-100), $4 \mathrm{mM}$ de $\mathrm{MgCl}_{2}, 10$ pmoles de cada iniciador, $100 \mathrm{ng}$ de ADN de P. falciparum, 200 $\mu \mathrm{M}$ de cada dNTP y 2,5 U de Taq polimerasa (PROMEGA). Las muestras se sometieron al siguiente perfil de amplificación: un ciclo de 5 minutos a $95^{\circ} \mathrm{C}$ y 5 minutos a $75^{\circ} \mathrm{C}, 40$ ciclos de denaturación a $95{ }^{\circ} \mathrm{C}$ durante un minuto, anillaje a $39^{\circ} \mathrm{C}$ durante 2 minutos (temperatura calculada a partir de la composición de bases de los oligos) y extensión a $72{ }^{\circ} \mathrm{C}$ y un ciclo final a $72{ }^{\circ} \mathrm{C}$ durante 5 minutos. El control de amplificación se llevó a cabo por electroforesis en gel de agarosa al $1 \%$ en buffer TBE (Tris- $\mathrm{HCl}$ $89 \mathrm{mM}$ pH 8,0, ácido bórico 89 mM, EDTA 2,5 $\mathrm{mM})$.

El producto de amplificación del tamaño esperado se purificó mediante aislamiento de la banda correspondiente obtenida en geles de agarosa y se clonó utilizando el sistema pMOSBlue de Amersham. La reacción de ligación inserto-vector (en relaciones molares 1:1, 2:1y 7,5:1) se llevó a cabo a $16{ }^{\circ} \mathrm{C}$ durante 16 horas y las bacterias pMOSblue fueron transformadas mediante choque térmico. El rastreo de colonias posibles recombinantes se llevó a cabo por PCR, utilizando como plantilla el lisado celular de cada colonia posible recombinante (colonias blancas); este lisado se obtuvo resuspendiendo cada colonia en $50 \mu \mathrm{l}$ de agua estéril, llevando a ebullición durante 5 minutos y centrifugando a 15.000 rpm durante 5 minutos. La reacción de amplificación se llevó a cabo en las condiciones descritas anteriormente y el control se hizo por electroforesis en gel de agarosa al 1\%, para determinar cuáles de las colonias presentaban el inserto de interés.

Una vez se obtuvo una colonia recombinante se procedió a confirmar que el fragmento clonado 
correspondiera al fragmento de $963 \mathrm{pb}$ del gen pfmdr1; se aisló ADN plasmídico y se hizo un ensayo de restricción utilizando las enzimas $H i n d$ III y $\mathrm{Bg} / \mathrm{II}$. El tamaño de los fragmentos esperados se calculó a partir del mapa del vector y de la secuencia del fragmento.

\section{Cultivo y sincronización de parásitos}

Se utilizaron las cepas colombianas FCB-1, FCB2 y dos cepas de referencia: Haití 135 (sensible) y Palo Alto (resistente), cultivadas según el método de Trager y Jensen (16). Los cultivos se sincronizaron utilizando un método de sincronización estricta (17), el cual combina tratamientos sucesivos de sorbitol (18)-Percoll (19)-sorbitol. Después del último tratamiento con sorbitol, los parásitos fueron mantenidos en cultivo hasta alcanzar las 20, 44 o 48 horas de desarrollo; en ese momento se recolectaron y se liberaron del eritrocito, por tratamiento con diez volúmenes de saponina al $0,15 \%$ en HBS (HEPES $0,02 \mathrm{M}, \mathrm{pH} 7,4, \mathrm{NaCl} 0,16 \mathrm{M}$ ) a $37^{\circ} \mathrm{C}$ durante 15 minutos; se lavaron dos veces con HBS centrifugando cada vez a $5.000 \mathrm{rpm}$. Por último, el pellet de parásitos se guardó a $-70^{\circ} \mathrm{C}$ hasta el momento de la extracción de ARN.

\section{Extracción de ARN}

Se tomaron $2 \times 10^{9}$ parásitos, los cuales fueron lisados con solución que contenía $4 \mathrm{M}$ de isotiocianato de guanidina, $25 \mathrm{mM}$ de citrato de sodio $\mathrm{pH} 7,0,0,5 \%$ de sarkosilato de sodio y 0,1 $M$ de $\beta$-mercapto-etanol; las proteínas fueron separadas mediante extracción fenol-cloroformo. EI ADN nuclear fue fragmentado mediante homogenización con aguja No. 20 y separado por ultracentrifugación a $42.000 \mathrm{rpm}$ durante 20 horas a $20^{\circ} \mathrm{C}$ (ultracentrífuga Hitachi SCP7OH2) en colchones de cloruro de cesio (5,7 M). El pellet de ARN fue resuspendido en solución de Tris $10 \mathrm{mM} \mathrm{pH} \mathrm{7,4,} \mathrm{EDTA} 5 \mathrm{mM}, 0,1 \%$ SDS y precipitado con 2,5 volúmenes de etanol en presencia de acetato de sodio $0,3 \mathrm{M}$; el ARN recuperado por centrifugación se lavó con isopropanol al 70\%, se secó al vacío y se resuspendió en agua tratada con dietil- pirocarbonato (DEPC) (20). La cantidad y concentración del ARN extraido se determinó por espectrofotometría a $260 \mathrm{~nm}$.

\section{Slot-blot de ARN total}

El ARN se denaturó a $65^{\circ} \mathrm{C}$ durante 15 minutos en tres volúmenes de solución $(1: 1 \mathrm{v} / \mathrm{v})$ de formaldehído al $37 \%$ y $20 x S S C(\mathrm{NaCl} 3 \mathrm{M}$, citrato de sodio $0,3 \mathrm{M}, \mathrm{pH} 7,0$ ); se filtró a través de una membrana de nylon (Amersham), utilizando el Bio-Dot SF Apparatus de Bio-Rad y se fijó durante 40 segundos con luz UV (254 nm), utilizando el Stratalinker UV Crosslinker de Stratagene. Las membranas se prehibridizaron a $42^{\circ} \mathrm{C}$ por dos horas en 6 XSSPE $(\mathrm{NaCl} 1,08 \mathrm{M}$, fosfato diácido de sodio $60 \mathrm{mM}$, EDTA $6 \mathrm{mM} \mathrm{pH}$ $7,0)$, solución bloqueadora Denhardt, sulfato de dextrano $5 \%$, formamida $50 \%$ y $100 \mu \mathrm{g} / \mathrm{ml}$ de ADN esperma de salmón denaturado por calentamiento a $90{ }^{\circ} \mathrm{C}$ y enfriado rápidamente en hielo. Finalizado el tiempo de prehibridación, se adicionó la sonda denaturada (vector pMOSBlue que contiene el fragmento de $963 \mathrm{pb}$ del gen pfmdr1, linearizado y marcado radiactivamente por amplificación con el fragmento Klenow de la ADN polimerasa utilizando iniciadores al azar, random priming), y se incubó a $40{ }^{\circ} \mathrm{C}$ durante 16 horas (21). Finalizada la hibridación, se hicieron dos lavados rápidos con 6xSSC, 0,1\% SDS, dos lavados de 20 minutos con $2 x S S C, 0.1 \%$ SDS y un lavado final con $0,1 \times S S C, 0,1 \%$ SDS a temperatura ambiente. Las membranas se dejaron secar y se expusieron en películas fotográficas MP de Amersham a $-70^{\circ} \mathrm{C}$.

\section{Resultados y discusión}

\section{Preparación de la sonda}

La reacción en cadena de la polimerasa nos permitió amplificar un fragmento ADN de $P$. falciparum, utilizando dos iniciadores específicos que reconocían el gen pfmdr1; estos iniciadores se diseñaron en tal forma que dieran lugar a un producto de $960 \mathrm{pb}$ aproximadamente. Como se muestra en la figura 1, la reacción de amplificación mostró además del fragmento esperado, un fragmento de $300 \mathrm{pb}$ aproximadamente, que posiblemente correspondía a uniones menos específicas de los iniciadores en el mismo gen pfmdr1, a uniones en el gen pfmdr2, con el cual presenta un porcentaje de homología del $53 \%$ (6) o a unión con otros genes relacionados. El fragmento del tamaño esperado fue purificado, 


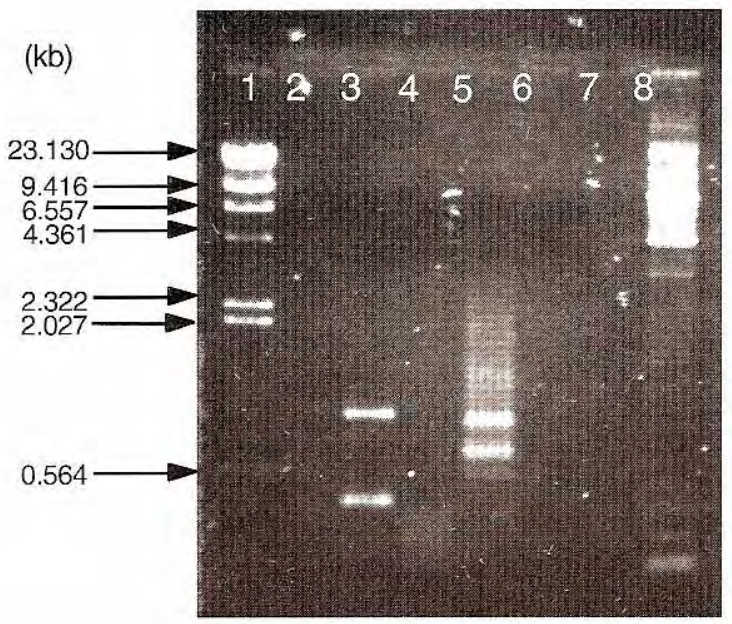

Figura 1. Amplificación por PCR de un fragmento del gen pfmdr1 utilizando ADN purificado de Plasmodium falciparum y dos iniciadores específicos diseñados con base en la secuencia del gen informada por Foote en 1989 (7). Como control positivo de la reacción se amplificó la secuencia repetitiva PfCOL 692 presente en el genoma del parásito y como control negativo todos los componentes de la reacción excepto el ADN plantilla. Carril 1: Marcador de tamaño:ADN $\lambda$ Hind III. Carril 3:Productos de amplificación a partir de ADN de $P$. falciparume iniciadores específicos para el gen pfmdr1. Carril 4: control negativo de amplificación. Carril 5:Control positivo de amplificación. Secuencia repetitiva PfCOL 692. Carril 8: Marcador de tamaño: Ladder 123 bp.

clonado en el vector pMOSBlue y verificado mediante un ensayo de restricción usando las enzimas Hind III y Bgl II; los tamaños de los fragmentos obtenidos en la digestión enzimática correspondieron a los calculados con base en el mapa del vector y la secuencia del gen pfmdr1, asegurándonos que el fragmento clonado correspondía al gen pfmdr1 y, por tanto, podía utilizarse para el reconocimiento del mensajero en ensayos posteriores.

\section{Extracción de ARN}

El objetivo principal de este trabajo fue el estudio de la expresión del gen pfmdr1 en cepas colombianas de $P$. falciparum durante el ciclo de vida asexual. Esto implicaba tener parásitos sincrónicos de cada cepa en diferentes estadios de desarrollo en cantidad suficiente como fuente de ARN. Para obtener cultivos con parasitemias altas, creciendo sincrónicamente, se utilizó un protocolo de sincronización estricta (17), combinado con condiciones de cultivo que permiten obtener invasiones altas (22). El protocolo de sincronización incluye un tratamiento con sorbitol al 5\% (18) cuando en el cultivo predominan las formas jóvenes o anillos. Este tratamiento lisa las formas maduras del parásito, dejando una población de anillos cuya edad puede variar de 0 a 20 horas. La concentración de las formas maduras se hizo mediante colchones de Percoll (19) cuando el cultivo había alcanzado una población de esquizontes superior al 1\%. Este tratamiento permite obtener preparaciones ricas en esquizontes (50-90\% de parasitemia), que al ser regresadas a cultivo con glóbulos rojos frescos utilizando hematocritos bajos $(0,5-1,0 \%)$ y altas parasitemias $(20 \%)$, permiten invasiones altas; finalmente, después de un tiempo de incubación de 10-12 horas, el cual define el rango de edad de los parásitos, el cultivo se sometió de nuevo a un tratamiento con sorbitol al $5 \%$. La combinación de estos protocolos nos permitió recolectar parásitos sincrónicos de 20, 44 y 48 horas de desarrollo para cada una de las cepas estudiadas (FCB-1, FCB-2, Haití 135 y Palo Alto).

Para la extracción de ARN, se utilizó un protocolo que permite obtener un ARN intacto, libre de otras macromoléculas como ADN y proteínas que puedan interferir en la detección del mensajero del gen en estudio (20). La lisis celular se lleva a cabo en presencia de isotiocianato de guanidina, agente caotrópico fuerte que denatura y solubiliza proteínas, permitiendo su separación posterior mediante extracción fenol-cloroformo, mientras que el ADN nuclear fraccionado mediante la homogenización con aguja No. 20 es separado por ultracentrifugación en colchones de cloruro de cesio. Este protocolo nos permitió extraer ARN de cada estadio de desarrollo del parásito en cantidad suficiente para los ensayos de slot blot; en algunas ocasiones en las que se presentó contaminación con ADN, fue necesario un tratamiento adicional con ADNasa I a $37^{\circ} \mathrm{C}$ durante 15 minutos, seguida de extracción fenólica y precipitación etanólica, tratamiento que nos permitió obtener un ARN libre de ADN, cuya ausencia se verificó mediante electroforesis en geles de agarosa al $1 \%$.

$5 \mu \mathrm{g}$ de ARN total de parásitos de 20, 44 y 48 horas de desarrollo de las cepas FCB-1, FCB-2, 
Palo Alto y Haití 135, fueron inmovilizados sobre membranas de nylon y utilizados para detectar el mensajero del gen por hibridización con el plásmido recombinante que contenía una secuencia de $963 \mathrm{pb}$ del gen pfmdr1.

\section{Análisis de la expresión del gen pfmdr1 a lo largo del ciclo de vida asexual de $P$. falciparum}

Estudios realizados anteriormente mostraron que el gen pfmdr1 se expresa en forma diferencial a lo largo del ciclo de vida asexual; sin embargo, el patrón de expresión encontrado varía de acuerdo con la cepa estudiada. Foote, en 1990, al estudiar las cepas 3D7 (CQS) y FAC8 (CQR), encontró una mayor expresión del gen en parásitos en el estadio de esquizonte (7), mientras que Ekong, al trabajar con la cepa Wmef (CQR), encontró una marcada disminución de la expresión en este estadio en comparación con el estadio de anillo y trofozoito (23). Por último, Volkman señaló la ausencia del transcrito en los estadios de anillo y esquizonte, al trabajar con la cepa K1 (CQR) (24).

En este estudio, al analizar cuatro cepas de diferente origen, encontramos dos patrones de expresión distintos (figura 2), uno para las cepas colombianas FCB-1 y FCB-2 (CQR), y otro para las cepas de referencia Palo Alto (CQR) y Haití 135 (CQS). Para las cepas colombianas la expresión del gen es baja en las formas jóvenes (20 h); luego, aumenta en parásitos en segmentación (44 h), y disminuye en parásitos que han completado la esquizogonia y se encuentran próximos a liberar los nuevos merozoítos formados (48h). Este patrón de expresión es similar al encontrado por Foote para las cepas 3D7 y FAC8, pero diferente al encontrado por Ekong para la cepa Wmef y al encontrado por Volkman para la cepa K1.

Para las cepas utilizadas como referencia, Palo Alto (resistente) y Haití (sensible), encontramos niveles altos del transcrito en parásitos jóvenes (20 h) y disminución de la expresión en parásitos de 44 y 48 horas de desarrollo. Con respecto a estas dos cepas, no puede asegurarse que la máxima expresión se de en el estadio de anillo, pues no se estudió la expresión en parásitos entre

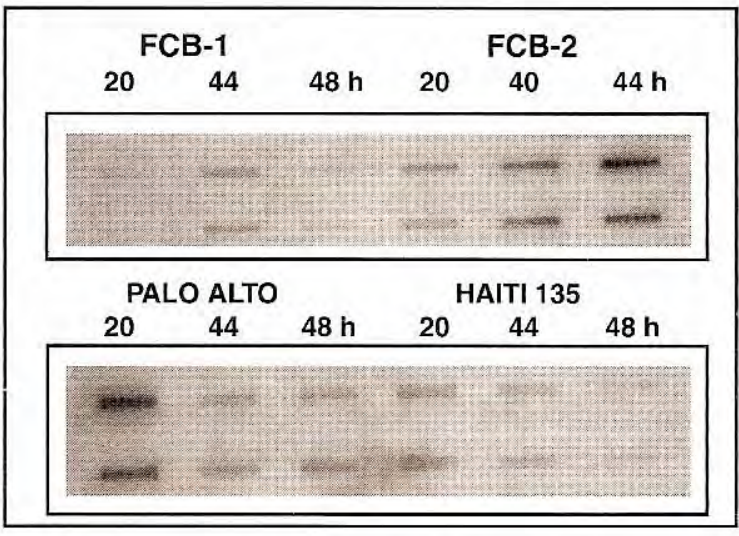

Figura 2. Expresión del gen pfmdr1 a lo largo del ciclo de vida asexual de diferentes cepas de Plasmodium falciparum. Se llevó a cabo mediante un ensayo de slot-blot, utilizando $5 \mu \mathrm{g}$ de ARN total de parásitos de cada cepa a las 20,44 y 48 horas de desarrollo, utilizando como sonda ${ }^{32} \mathrm{P}$. pMOS-pfmdr1. A. Autoradiografía de los ensayos por duplicado con las cepas colombianas FCB-1 (CQR) y FCB-2 (CQR). B. Autoradiografía de los ensayos por duplicado con las cepas de referencia Palo Alto (CQR) y Haití 135 (CQS). Como control negativo se utilizaron $5 \mu \mathrm{g}$ de tARN de levadura y $5 \mu \mathrm{g}$ de ARN ribosamal de E. coli, con los que no se obtuvo señal.

las 20-40 horas de desarrollo. Es posible, entonces, que el patrón de expresión coincida con el propuesto por Volkman, con un pico de expresión en el estadio de trofozoito maduro (36 horas aproximadamente) o que definitivamente para estas cepas la máxima expresión del gen se de en parásitos jóvenes y presente un patrón de expresión completamente diferente a los encontrados en otras cepas. Dado que en este trabajo se observaron dos patrones de expresión distintos al estudiar cuatro cepas (figura 2) y que anteriormente se había informado sobre tres patrones de expresión para otras cuatro $(7,23$, 24), es posible sugerir que el gen pfmdr1 no presenta un patrón de expresión uniforme a lo largo del ciclo de vida asexual en cepas de diferentes orígenes y con diferente respuesta frente a medicamentos.

\section{Expresión del gen pfmdr1 en cepas con diferente respuesta a medicamentos}

En algunos estudios se ha asociado un aumento en la expresión del gen pfmdr1 con la resistencia a múltiples medicamentos $(7,23-26)$; sin embargo, en otros se plantea que la sobre-expresión 
del gen no es necesaria para conferir este fenotipo $(27,28)$.

Este trabajo estudió la expresión del gen pfmdr1 en dos cepas colombianas, FCB-1 y FCB-2, y en dos cepas utilizadas como referencia, una resistente (Palo Alto) y otra sensible (Haití 135), para establecer la existencia o ausencia de relaciones entre el nivel de expresión del gen y la respuesta a medicamentos exhibida por las cepas. En un estudio anterior, las cepas FCB-1, FCB-2 y Palo Alto, fueron clasificadas como resistentes a la cloroquina, la mefloquina y la amodiaquina, usando el microensayo de la OMS y la prueba radiométrica. Haití 135 fue clasificada como cloroquino-susceptible mediante un ensayo conocido como rapid test (29). Las cepas de referencia fueron elegidas bajo la premisa de que el fenotipo resistente estaba asociado con la sobre-expresión del gen pfmdr1; de este modo, las cepas resistentes deberían tener niveles de expresión del gen semejantes al de la cepa Palo Alto, mientras que en las cepas sensibles la expresión sería comparable a la encontrada en Haití 135.

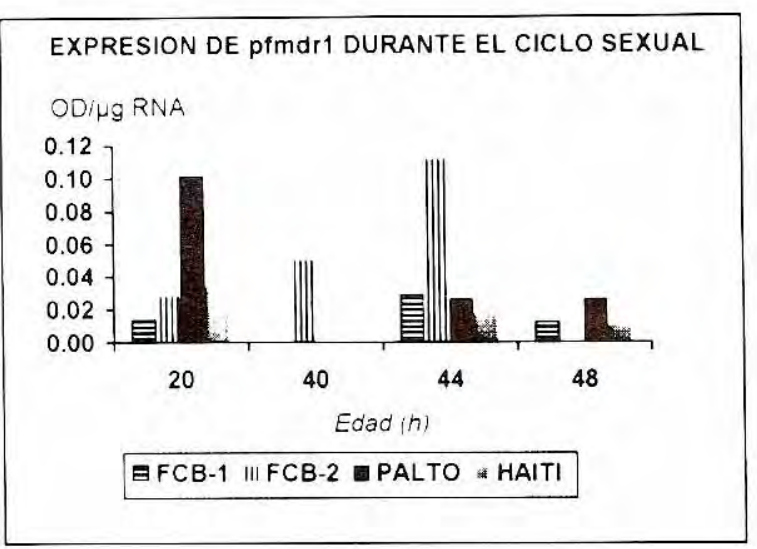

Figura 3. Expresión del gen pfmdr1 durante el desarrollo asexual del Plasmodium falciparum. Se estudiaron las cepas colombianas FCB-1 y FCB-2 y dos cepas de referencia Haití (susceptible) y Palo Alto (resistente). Se muestra una gráfica de densidad óptica por microgramo de ARN de P. falciparum versus la edad de los parásitos (h). Los valores de O.D por microgramo de ARN total son estimativos ya que las lecturas densitométricas fueron hechas sobre películas con 70 horas de exposición.
Tal como se muestra en la figura 3, al comparar el nivel de expresión del gen pfmdr1 entre las cepas de referencia Haití 135 y Palo Alto en parásitos de 20 horas, observamos una expresión tres veces mayor en la cepa resistente, mientras que al comparar los niveles de expresión entre las cepas resistentes FCB-1 y FCB-2 en parásitos de 44 horas de desarrollo, encontramos una expresión del gen cuatro veces mayor en la cepa FCB-2. Aunque la expresión del gen pfmdr1 fue mayor en las cepas más resistentes a cloroquina, mefloquina y amodiaquina, es posible sugerir que la expresión del gen no está directamente relacionada con el fenotipo resistente en experimentos realizados in vitro, pues la gran diferencia en los niveles de expresión del gen entre las cepas colombianas no coincidió con el comportamiento similar que estas cepas presentan frente a estos medicamentos (29).

Estos resultados sugieren, además, que la mayor expresión del gen pfmdr1 no siempre coincide con una resistencia mayor a los fármacos, lo cual apoya la hipótesis que plantea la existencia de otros genes relacionados que pueden operar conjuntamente para producir el fenotipo resistente. No obstante, es necesario precisar que no se estudió la expresión del gen en parásitos entre las 20 y 40 horas de desarrollo, período en el cual el parásito degrada hemoglobina de manera activa y que, por tanto, los mecanismos tanto de acción como de resistencia del medicamento están operando.

Por otro lado, algunos autores han planteado como base de la resistencia un marcado aumento en el eflujo de medicamentos desde el interior de las células (4). El ensayo denominado rapid test es una prueba utilizada para determinar resistencia a cloroquina y se basa en el eflujo diferencial del medicamento en parásitos resistentes y en parásitos sensibles. Debido a que el verapamil inhibe el mecanismo de rápido eflujo, los parásitos cloroquinorresistentes exhiben un incremento detectable en la acumulación a cloroquina cuando son incubados en presencia de este compuesto; por su parte, los parásitos cloroquinosusceptibles muestran una ligera disminución en la acumulación del fármaco. En ese ensayo, cepas que presentan 
grandes diferencias entre el sistema con verapamil y el sistema sin verapamil, son catalogadas como resistentes a cloroquina, mientras que cepas con diferencias pequeñas son catalogadas como sensibles (30).

En un estudio anterior, FCB-1, FCB-2 y Palo Alto fueron clasificadas como cloroquinorresistentes, indicando un rápido eflujo del medicamento en estas cepas, mientras que Haití 135 fue catalogada como cloroquinosensible, indicando un élujo lento del mismo; de acuerdo con esos resultados y los presentados en este trabajo, se puede sugerir que el fenotipo de rápido eflujo parece no estar directamente asociado con la expresión del gen pfmdr1, pues la gran diferencia entre los niveles de expresión del gen en las cepas colombianas (figura 3) no coincide con la expulsión similar de cloroquina que presentan estas cepas.

Otros autores han planteado que la proteína producto del gen pimdr1 puede actuar no como una bomba de eflujo del medicamento, sino como regulador en la acumulación del mismo (10); de ese modo, las cepas con una mayor expresión del gen favorecerían la acumulación de cloroquina, provocando una mayor sensibilidad al medicamento, y las cepas con menor expresión presentarían menor sensibilidad. De acuerdo con este planteamiento, se esperaría que las cepas más sensibles presentaran niveles más altos del transcrito y las más resistentes los niveles más bajos; sin embargo, esto no ocurre con las cepas analizadas en este estudio; por el contrario, la cepa susceptible a cloroquina es una de las que presenta los niveles más bajos de expresión, mientras que las cepas resistentes presentan mayores niveles del transcrito. De estos resultados podemos sugerir que la expresión del gen pfmdr1 no está directamente relacionada con la sensibilidad a cloroquina como plantean algunos autores $(10,11)$.

Este es el primer estudio realizado en cepas colombianas sobre las bases moleculares que ocasionan la resistencia a cloroquina; de los resultados presentados en este estudio se puede sugerir que, para estas cepas, la expresión del gen pfmdr1 no está directamente relacionada con el fenotipo de rápido eflujo ni con la resistencia a cloroquina, mefloquina y amodiaquina.

\section{Agradecimientos}

Este proyecto fue financiado por el Organismo Internacional de Energía Atómica (OIEA), proyecto (01/6/007); por el Instituto Colombiano para el Desarrollo de la Ciencia y la Tecnología Francisco José de Caldas, Colciencias, proyecto (2104-04170-95), y por el Instituto Nacional de Salud, INS.

\section{Referencias}

1. Wellems TE. Molecular genetics of drug resistance in Plasmodium falciparum. Parasitol Today 1991;7:110-2.

2. Slater FG. Chloroquine mechanism of drug action and resistance in Plasmodium falciparum. Pharmac Ther 1993; 57:203-35.

3. Peterson DS, Walliker D, Wellems TE. Evidence that a point mutation in dihydrifolate reductase-thymidylate confers resistance to pyrimethamine in falciparum malaria. Proc Natl Acad Sci USA 1988;5:9114-8.

4. Bray PG, Howells RE, Ritchie GY, Ward SA. Rapid chloroquine eflux phenotype in both chloroquine-sensitive and chloroquine resistant Plasmodium falciparum. A correlation of chloroquine sensivity with energy-dependent drug acumulation. Biochem Pharmacol 1992;44:1317-24.

5. Juliano RL, Ling V. A surface glycoprotein modulating drug permeability in Chinese hamster ovary cell mutants. Biochem Biophys Acta 1976;455:152-62.

6. Wilson CM, Serrano AE, Wasley A, Bogenschutz MP, Shankar AH, Wirth DF. Amplification of a gene related to mammalian MDR genes in drug-resistant Plasmodium falciparum. Science 1989;244:1184-86.

7. Foote SJ, Thompson JK, Cowman AF, Kemp DJ. Amplification of the multidrug resistance gene in some chloroquine-resistant isolates of $P$. falciparum. Cell 1989; 57:921-30.

8. Wellems TE, Panton LJ, Gluzman IY, Rosario UE, Gwadz RW, Walker A. Chloroquine resistance not linked to MDR-like genes in a Plasmodium falciparum cross. Nature 1990; 345:255-8.

9. Barnes DA, Foote SJ, Galatis D, Kemp DJ, Cowman AF. Selection for high level chloroquine resistance results in deamplification of the pfMDR 1 gene and increased sensitivity to mefloquine in Plasmodium falciparum. EMBO J 1992;11:3067-75.

10. Van Es HHG, Karcz S, Chu F, Cowman AF, Vidar S, Gross D, et al. Expression of the plasmodial pfMDR 1 gene in mammalian cells is associated with increased susceptibility to chloroquine. Mol Cell Biol 1994;14:2419-28. 
11. Van Es HHG, Renkema H, Aerts H, Schurr A. Enhanced lysosomal acidification leads to increased chloroquine accumulation in $\mathrm{CHO}$ cells expressing the pfmdr1 gene. Mol Biochem Parasitol 1994;14:2419-2428.

12. Volkman SK, Cowman AF, Wirth DF. Fuctional complementation of de STE6 gene of Saccaromyces cerevisiae with the pfmdr1 gene of Plasmodium falciparum. Proc Natl Acad Sci 1995;92:8921-5.

13. Sanchez CP, Wunsch S, Lanzer M. Differences in import kinetics are genetically linked with the chloroquineresistant phenotype. J Biol Chem 1997;272:2652-8.

14. Wunsch S, Sanchez CP, Gekle M, Grosse L, Wiesner J, Lanzer M. Differential stimulation of the $\mathrm{Na}^{+} / \mathrm{H}^{+}$exchanger determines chloroquine uptake in Plasmodium falciparum. J Cell Biol 1998;140:335-45.

15. Su XZ, Kirkman LA, Fujioka H, Wellems TE. Complex polymorphisms in a similar to $330 \mathrm{KD}$ a protein are linked to chloroquine-resistant $P$. falciparum in Southeast Asia and Africa. Cell 1997;91:593-603.

16. Trager W, Jensen JB. Human malaria parasites in continuous culture. Science 1976;193:673-5.

17. Rojas MO, Wasserman M. Supersincronización del crecimiento in-vitro del $P$. falciparum. Biomédica 1987;7:621-4.

18. Lambros C, Vanderberg JP. Synchronization of the Plasmodium falciparum erythrocyte stages in culture. J Parasitol 1979; 65:418-20.

19. Rivadeneira E, Wasserman M, Espinal C. Separation and concentration of schizonts of Plasmodium falciparum by Percoll gradients. J Protozool 1983;30:367-70.

20. Rojas MO. Expresión específica de estado del gen de calmodulina en Plasmodium falciparum. Tesis Doctorado. Universidad Nacional. Departamento de Química. 1995.

21. Wasserman M, Rojas MO, Pinilla G, Contreras J.
Manual de técnicas básicas en biología molecular. Bogotá:INS 1994.

22. Vernot JP, Wasserman M. P. falciparum increased and multiple invasion during short periods of time. J Protozool 1990; 37: 47-9.

23. Ekong RM, Robson KJ, Baker DA, Warhurst DC. Transcripts of the multidrug resistance genes in chloroquine sensitive and chloroquine resistant in $P$. falciparum. Parasitol 1993;106:107-12.

24. Volkman SK, Wilson CM, Wirth DF. Stage-specific transcripts of the P. falciparum pfmdr1 gene. Mol Biochem Parasitol 1993;57:203-12.

25. Cowman AF, Galatis D, Thompson JK. Selection for mefloquine resistance in Plasmodium falciparum is linked to amplification of the pfMDR 1 gene and cross-resistance to halofantrine and quinine. Proc Natl Acad Sci 1994;91: 1143-47.

26. Peel SA, Brigth P, Yount B, Handy J, Baric RS. A strong association between mefloquine and halofantrine resistance and amplification, overexpression, and mutation in the P-glycoprotein gene homolog (pfmdr1) of Plasmodium falciparum in vitro. Am Soc Trop Med Hyg 1994;51:64851.

27. Lim AS, Galatis D, Cowman AF. Plasmodium falciparum: amplification and overexpression of pfmdr 1 is not necessary for increased mefloquine resistance. Exp Parasitol 1996;83:295-303.

28. Lim AS, Cowman AF. Plasmodium falciparum: Chloroquine selection of a cloned line and DNA rearregements. Exp Parasitol 1996;83:283-94.

29. Chaparro J, Wasserman M.Comparación de técnicas in vitro para detectar resistencia de Plasmodium falciparum a medicamentos. Biomédica 1999;19:103-14.

30. Wernsdorfer WH, Payd D. Drug sensitivity test in malaria parasites. BullWHO 1980;58:1765-1800. 